\title{
Management of Solid Waste Deposited in Landfill of Used Motor Oil Recovery Units Via Production of Zeolite A With Proper Cation Exchange Capacity by Fusion Technique
}

Fatemeh Amir Aslanzadeh Mamaghani

Sahand University of Technology

Amin Salem ( $\sim$ salem@sut.ac.ir)

Sahand University of Technology

Shiva Salem

Urmia University of Technology

\section{Research Article}

Keywords: Solid waste, used motor oil, fusion, zeolite A, hydroxysodalite, cation exchange capacity

Posted Date: October 19th, 2021

DOl: https://doi.org/10.21203/rs.3.rs-905624/v1

License: (c) (1) This work is licensed under a Creative Commons Attribution 4.0 International License.

Read Full License 


\section{Abstract}

The efficient management of solid waste deposited in the landfill of used motor oil recovery units is an important environmental challenge which is originated from the regeneration by bentonite as an effective adsorbent. The current study was attempted to convert the black waste into zeolite based compounds through fusion technique. The collected waste powder were mixed with sodium hydroxide, and boehmite followed by treatment at different temperatures, $600-800^{\circ} \mathrm{C}$. Then, the obtained precursors were hydrothermally converted to zeolite A or hydroxysodalite. The effect of parameters like alkalinity, boehmite, and sodium aluminate ratios, fusion temperature, and aging time on structural characteristics, and cation exchange capacity (CEC) were studied in details. The potential of solid waste in the production of zeolite A is significantly affected by mentioned factors which govern on purity, crystallinity, morphology, and CEC. The cation exchange capacity about $190 \mathrm{mg} \mathrm{g}^{-1}$ can be achieved by alkali, and boehmite ratios of 2.00 , and 0.53 , respectively. The microstructural analyses showed the morphological evolution from rounded shape to sharp edges by fusion at $800^{\circ} \mathrm{C}$ due to appropriate recrystallization. Besides, hydrosodalite powder with extended surface area, $77 \mathrm{~m}^{2} \mathrm{~g}^{-1}$, could be produced by limited content of boehmite in the presence of $\mathrm{NaAlO}_{2}$.

\section{Introduction}

A huge content of used motor oil is generated in the world which is serious concern of governments due to creating a verity of environmental problems, required responsible management. The damage of environment occurs through the contamination of soil, water stream, and air with polycyclic aromatic hydrocarbons, metal organic additives, soot, and degraded products identified as priority hazardous pollutants (Guerin, 2008). When these toxic materials are dumped into environment even at trace content, the intoxications of media affect the human life, and living things, causing cancers, assimilation, and skin diseases. Consequently, the application of eco-friendly methods for the treatment of used motor oil is of great significance before deposition, and release into the environment. Recycle of such carcinogenic materials are well-known as beneficial pathway in decline of toxicity, and refined oil cost. Conventionally, the recycle of used motor oil is carried out through different combined processes such as vacuum distillation, liquid-liquid extraction, adsorption, and hydrofinishing to enhance the physico-chemical properties of final product (Jafari and Hassanpour, 2015).

Bentonite is a clay mostly consisting montmorillonite which is a member of a 2:1 clay minerals, having two tetrahedral silica layers surrounded an octahedral alumina layer (Shattar et al., 2020).

Montmorillonite is classified as sodium or calcium types, concerning exchangeable ion between the sheets. Bentonite resources are created by alteration of volcanic ash which contain an excess of silica, and lower content of alumina. The vast majority of bentonite ores are calcium type which found wide applications in the regeneration, and purification of industrial liquors (Savic, et al., 2014). The fine particles, sheet-like structure, large surface area, negative layer charge, and exchangeable cations are beneficial, leading to strong affinity for the application in the adsorption processes. On the other hand, the effectiveness of bentonite depends on montmorillonite proportion, and level of impurities like opal CT, 
cristobalite, quartz, calcite, feldspar, and mica (Savic, et al., 2014; Salem and Saghapour, 2015; Zivica and Palou, 2015). Although Ca-bentonite can be applied naturally for refining used motor oil, the activated clay is preferred to use because of effective reduction in the adsorbent consumption (Shabanzade et al., 2018; Shabanzade et al., 2019).

Zeolite A, well-known as Linde Type A (LTA), is a fantastic material due to non-toxicity, high porosity, cation exchange capacity, and is widely employed in laundry detergent compositions, purification of gas, and liquid, wastewater treatment, and catalyst support (Collins et al., 2020; Muriithi et al., 2020; Dusselier and Davis, 2018; Weitkamp, 2000). The initial route for synthesis of zeolite $A$ is formation of an aluminosilicate gel from sodium silicate, and sodium aluminate which is recrystallized hydrothermally (Collins et al., 2020). The increased request demand for zeolite A needs to innovate the facile production techniques based on employment of low-cost materials like natural, by-products, and solid wastes (Yoldi et al., 2019). The hydrothermal method is a conventional route for the fabrication of zeolite A. The high crystalline LTA phase can be created from bentonite with adding resource of aluminum in the presence of sodium carbonate (Ma et al., 2010). Zeolite A was also produced by the hydrothermal method using kaolin (Abdullahi, et al., 2017; Johnson and Arshad, 2014) fly ash (Muriithi et al., 2020; Yang et al., 2019), solid waste of sanitary ware industry (García-Villén et al., 2018), crushed stone powder and aluminum ash (Kuroki et al., 2019), coal gangue (Jin et al., 2021), alum sludge (Rozhkovskaya et al., 2021a, b), and red mud (Belviso et al., 2020). Although hydrothermal method was applied for the fabrication of zeolite $A$ from different wastes, it is difficult to produce the crystalline, and relatively pure products from some impure resources like low grade kaolin or solids containing chemically inert impurities like quartz, cristobalite, and opal CT (Ayele et al., 2016). Hence, it is of great importance to innovate alternative treatment approach respect to hydrothermal route. The fusion pre-treatment with sodium hydroxide followed by hydrothermal treatment of amorphous phase was found attractive interest due to facility to achieve a product with high purity. In the fusion step, the crystalline phases are converted into aluminosilicates which easily recrystallized in hydrothermal step. Recently, zeolite A was fabricated from low grade kaolins by fusion pre-treatment method which is potentially intensive, and economically effective route to scale-up industrially (Foroughi et al., 2021). The fused sodium aluminosilicate obtained from cupola slag, sodium hydroxide, and aluminum sludge can be converted into zeolite A (Anuwattana and Khummongkol, 2009).

Although adsorption onto Ca-bentonite is effective route for the appreciable improvement of base oil quality, the contaminants are transferred onto adsorbent, leading to creation of secondary pollution. The deposition of solid waste in the landfill of used oil recovery units, which contains highly toxic compounds like asphalt, fuels, soot, and polyalphaolefines, caused serious environmental problems. This solid waste is traditionally managed via incineration which is uneconomical, and result in dangerous dust dissemination. The conversion of waste into zeolite A seems to be an appropriate, and economical alternative method respect to incineration which could help to restore the natural resources. The objective of current work is to propose an intensive process based on fusion pre-treatment for the production of zeolite A from the mentioned waste if a large scale fabrication would be considered to strictly control the contamination accumulated in the landfill. It was demonstrated the organic, and inorganic impurities like 
asphalt, and opal CT in the selected waste could be deleted by alkali fusion. Due to low content of alumina in the waste employed for the production of zeolite in this research, the composition was initially modified by sodium hydroxide, and boehmite mixture to compensate aluminum deficiency in fusion step, and subsequently sodium aluminate was introduced into the fused compound in the hydrothermal process. Detailed characterizations were also performed to well-understand the role of process variables on structure of products.

\section{Materials And Methods}

\subsection{Solid waste collection and used materials}

The used motor oil collected from different car service stations was refined by a company in Marand town (East Azerbaijan Province, Iran) based on adsorption process explained as follows. After restoring the used oil for several days in especial tanks, the sediments were separated by gravity, and then the pretreated oil was mixed with a natural Ca-bentonite powder, $<74 \mu \mathrm{m}$, obtained from Soltaniyeh region located in the south-western of Zanjan province in Iran which is extensively employed as adsorbent by the related industries. The dehydration, and distillation were carried out by heating the obtained suspension from ambient temperature up to $400^{\circ} \mathrm{C}$ overnight in which the mixture was agitated continuously. The distillated compounds exiting from the top of agitating chamber were collected by a condenser. The obtained suspension was sent to filter press for separation of refined oil from adsorbent. The remained black material was collected as solid waste in a huge quantity. After well mixing 10 tons of waste accumulated in the landfill, $50 \mathrm{~kg}$ was selected for the production of zeolite-based compounds. The other chemicals used in the current study included sodium hydroxide $(\mathrm{NaOH}, 99 \%)$, and boehmite which is produced by Mineral Research Center of West Country in Iran.

\subsection{Zeolite production from solid waste}

The alkali fusion treatment of solid waste could remove the organic, and inorganic impurities like asphalt, and opal CT. To determine the proper content of sodium hydroxide for deletion of impurities, the alkali ratio (AR), $\mathrm{NaOH}$ /solid waste, was changed from 1.00 to 2.00 . In order to compensate the deficiency of alumina, the boehmite ratio (BR), boehmite/solid waste, raised from 0.40 to 0.53 by subsequently heat treatment at 600,700 , and $800^{\circ} \mathrm{C}$ in an electrical furnace. A wide range of sodium aluminate ratio (SAR), $\mathrm{NaAlO}_{2}$ /solid waste, $0.13-0.74$, was considered to demonstrate the combination of aluminum resources on product structure. After fusion step, $15 \mathrm{~mL}$ distilled water was added to thermally treated materials, resting for 3-24 $\mathrm{h}$ in a Teflon container to assess the effect of aging time on zeolite structure. The container was transferred into a steel autoclave to hydrothermally convert the aged aluminosilicates to zeolite based materials at $100{ }^{\circ} \mathrm{C}$ within $3 \mathrm{~h}$. A part of boehmite was replaced with sodium aluminate to identified the effect of aluminum resource on zeolite recrystallization. A wide range of sodium aluminate ratio (SAR), $\mathrm{NaAlO}_{2}$ /solid waste, $0.13-0.74$, was considered to demonstrate the combination of aluminum resources on product structure in which $\mathrm{NaAlO}_{2}$ was added to Teflon container in the hydrothermal step. The products were washed continually with distilled water to neutralize the obtained 
suspensions due to exiting excess sodium hydroxide. Then, the products were separated by filtration followed with drying in a laboratory oven at $60^{\circ} \mathrm{C}$ overnight.

\subsection{Solid waste and product characterizations}

The chemical composition of used waste was determined by Phillips PW1410 XRF (Nederland) spectrometer. The low angle X-ray diffraction was performed on used solid waste by Philips (Model PW1730, Nederland) using Cu-K $\alpha$ radiation $\left(\lambda: 1.5406^{\circ} \mathrm{A}\right)$, operated at $40 \mathrm{kV}$ and $30 \mathrm{~mA}$ in $2 \theta$ range of $0.8-10^{\circ}$ with scanning rate of $0.05^{\circ} \mathrm{s}^{-1}$. Also, the crystalline structural of waste, and produced powders were identified in $2 \theta$ range of $10-60^{\circ}$ by X-ray diffractometry (XRD, Model D-5000, Siemens, Germany), using Cu-Ka radiation with a step size of $0.02^{\circ}$, operating at $45 \mathrm{kV}$, and $40 \mathrm{~mA}$. The diffraction patterns were compared with the respective Powder Diffraction Files (PDF) data base to identify the crystallites of materials. FTIR spectra were recorded on the powders pelletized with $\mathrm{KBr}$ by Thermo infrared spectrometer (FTIR, Model AVATAR, USA) in the wave number range of $4000-400 \mathrm{~cm}^{-1}$. The differential thermal analysis (DTA), and thermal gravimetric analysis (TGA) were carried out with a heating rate of 10 ${ }^{\circ} \mathrm{C} \min ^{-1}$ within the temperature range of $25-1000{ }^{\circ} \mathrm{C}$ in the air atmosphere using a TA Instrument (DTATGA, Model Q600, USA).

The cation exchange capacity (CEC) of produced powders was measured to evaluate the ability of materials in removing $\mathrm{Ca}^{2+}$ cations. The powders were dried at $110^{\circ} \mathrm{C}$ within $1 \mathrm{~h}$, and maintained in a desiccator at room temperature. The dried powders were added into a beaker containing $50 \mathrm{~mL}$ $\mathrm{CaCl}_{2} \cdot 2 \mathrm{H}_{2} \mathrm{O}, 5 \mathrm{mmol} \mathrm{L}-1$, which was known as very hard water. After vigorously agitating at room temperature, the powders were separated by centrifugation, and the concentration of residual $\mathrm{Ca}^{2+}$ was determined by ion chromatography (Model, 930Compact Flex, Metrohm, Switzerland).

Field emission scanning electron microscopy was applied to identify the morphology of particles by Tescan (FESEM; Model MIRA3, Czech Republic). Nitrogen adsorption-desorption was carried out at -196 ${ }^{\circ} \mathrm{C}$ using a Quantacherom (Model 3000, Chem BET, USA) volumetric analyzer. The powders were degassed at $150{ }^{\circ} \mathrm{C}$ for $4 \mathrm{~h}$ before the measurements. The BET (Brunauer-Emmett-Teller) isotherm was adjusted to obtain the specific surface area, and pore volume. The BJH (Barrett- Joyner-Halenda) method was used to determine the pore size distribution.

\section{Results And Discussion}

\subsection{Characteristics of used solid waste}

The chemical composition of used solid waste is summarized in Table 1. The starting material applied in the current investigation is a high-silica compound in which the content of $\mathrm{SiO}_{2}$ is over $57 \%$. The alumina content which is the main oxide for the zeolite production, is below $9 \%$ which is insufficient to convert the waste into zeolite A. Consequently, the aluminum lack should be compensated by adding other Al resources like boehmite, and sodium aluminate. According to chemical analysis, the solid waste is an 
aluminosilicate with small content of alkali oxides. The $\mathrm{CaO}+\mathrm{MgO}$ content is approximately $8.8 \%$, which should be deleted during the zeolite fabrication. The $\mathrm{Fe}_{2} \mathrm{O}_{3}+\mathrm{TiO}_{2}$ content was found to be in small quantity, $<1.5 \%$, which could affect opacity, and whiteness of final product. The loss on ignition (LOI) is in the level of $21 \%$ which is due to volatile substances explained by the majority of organic impurities. The waste is described as a black material which is attributed to the presence of organics, and soot removed from the spent oil. Among the trace elements, the concentration of sulfur, and zinc seem to be noticeable which are added to adsorbent during the spent oil treatment.

Table 1

Chemical composition of used solid waste.

\begin{tabular}{|llll|}
\hline Oxide & Content $(\boldsymbol{w t} \%)$ & Element & Concentration $\left(\mathrm{mg} \mathrm{L}^{-1}\right)$ \\
\hline $\mathrm{SiO}_{2}$ & 57.56 & $\mathrm{Cl}$ & 279 \\
$\mathrm{Al}_{2} \mathrm{O}_{3}$ & 8.67 & $\mathrm{~S}$ & 4906 \\
$\mathrm{Fe}_{2} \mathrm{O}_{3}$ & 1.39 & $\mathrm{As}$ & 14 \\
$\mathrm{CaO}$ & 6.27 & $\mathrm{Ba}$ & 334 \\
$\mathrm{Na}_{2} \mathrm{O}$ & 0.54 & $\mathrm{Ni}$ & 19 \\
$\mathrm{~K}_{2} \mathrm{O}$ & 0.87 & $\mathrm{~Pb}$ & 68 \\
\hline $\mathrm{MgO}$ & 2.54 & $\mathrm{Rb}$ & 47 \\
\hline $\mathrm{TiO}_{2}$ & 0.13 & $\mathrm{Sr}$ & 215 \\
\hline $\mathrm{MnO}$ & 0.04 & $\mathrm{~V}$ & 21 \\
\hline $\mathrm{P}_{2} \mathrm{O}_{5}$ & 0.43 & $\mathrm{Y}$ & 36 \\
\hline $\mathrm{LOI}^{2}$ & 21.00 & $\mathrm{Zn}$ & 2142 \\
\hline & & $\mathrm{Zr}$ & 66 \\
\hline
\end{tabular}

The XRD pattern of used solid waste is represented in Fig. 1a, mainly consisting montmorillonite due to the reflection in $2 \theta$ range of $4-8^{\circ}$, and opal CT, with the limited content of calcite, and feldspar. The presence of montmorillonite, opal CT, and feldspar mean that $\mathrm{SiO}_{2}$ is in a high proportion based on chemical analysis. The lack of aluminum is due to presence of montmorillonite which is well-known as clay mineral with the lower content of Al compared to kaolinite. $\mathrm{Fe}_{2} \mathrm{O}_{3}$ was not detected in XRD pattern although the chemical composition shows the proportion of this oxide, $1.4 \%$. It seems that Fe was replaced with Al in the octahedral layer of clay mineral. The alumina content of waste is not at the level of significant value to achieve zeolite A. Inclusively; the other resources of alumina should be employed to convert the waste into zeolite $\mathrm{A}$. 
The FTIR spectrum of solid waste is indicated in Fig. 1b in which the main infrared absorption signals are identified at $470,512,791$, and $1085 \mathrm{~cm}^{-1}$ belong to the symmetrical stretching vibrations of $\mathrm{Si}-\mathrm{O}$ and, SiO-Si bonds in montmorillonite, opal CT, and feldspar. The signal at $1630 \mathrm{~cm}^{-1}$ is ascribed to $0-\mathrm{H}$ bending vibration, exhibiting that the used waste could adsorb water molecules while the wide signal centered at $3430 \mathrm{~cm}^{-1}$ is associated with the hydrogen bond vibration. The band appeared at $3620 \mathrm{~cm}^{-1}$ is assigned to Al-O-H, and or Mg-O-H vibrations in the octahedral layer of montmorillonite. The bands at 1375 , and $1458 \mathrm{~cm}^{-1}$ associate to stretching vibrations of $\mathrm{C}-\mathrm{H}$ in $-\mathrm{CH}_{3}$ groups. The signals at 2856 , and $2920 \mathrm{~cm}^{-1}$ correspond to the characteristic peaks of $\mathrm{C}-\mathrm{H}$ in methyl group due to adsorption of organic contaminants from the used oil. The baseline shift at $2000 \mathrm{~cm}^{-1}$ is in conformity with soot adsorbed onto the bentonite particle surface.

The change in the structure of waste during the thermal treatment was examined by DTA-TGA curves as plotted in Fig. 1c. The TGA plot can be divided into four regions. In the low-temperature region, 25-150 ${ }^{\circ} \mathrm{C}$, the slope change is very slow, corresponding to the loss of physically absorbed light hydrocarbons like fuels. A endothermic peak appeared at $120^{\circ} \mathrm{C}$ is due to the evaporation of light hydrocarbons. The absence of effective mass loss showed that the waste was dehydrated during the spent oil recovery which was performed at temperature above $400^{\circ} \mathrm{C}$. The sharp change in TGA curve is observable between 150 and $400^{\circ} \mathrm{C}$ because of heavy hydrocarbon ignition which were adsorbed onto the bentonite particles. DTA curve exhibited a glass transition temperature near to $390^{\circ} \mathrm{C}$ due to presence of asphaltic material adhered to the bentonite particles. This outcome released a large content of $\mathrm{CO}_{2}$, resulting in a sharp decrease in mass in higher temperatures, $400-725^{\circ} \mathrm{C}$. The exothermic reaction observed at the mentioned temperature range in which $11 \%$ of mass was lost, consequently. An abroad endothermic reaction in the interval of $400-725^{\circ} \mathrm{C}$ occurred because of dehydroxylation of montmorillonite. However, the dehydroxylation of opal CT also took place at temperatures lower than $725^{\circ} \mathrm{C}$. The occurrence of a mass loss above $725^{\circ} \mathrm{C}$ could be related to the ignition of remained organic materials.

The found $\mathrm{N}_{2}$ adsorption-desorption isotherms of solid waste is shown in Fig. $1 \mathrm{~d}$ which is similar to type III isotherm classified by International Union of Pure and Applied Chemistry (UIPAC). This category of isotherms is observed for the weak interactions with the adsorbent surface, commonly appeared for the nonporous or microporous materials. A loop between adsorption, and desorption curves was formed at relative pressure range of $0.35-0.99$ which indicated type $\mathrm{H} 3$ hysteresis. Although the slit-like mesopores exist in the waste structure, the pore are mainly distributed in the range of 2-8 $\mathrm{nm}$. The basic textural properties, including specific surface area, pore volume, average pore size were determined as $0.7 \mathrm{~m}^{2} \mathrm{~g}^{-1}$, $0.002 \mathrm{~cm}^{3} \mathrm{~g}^{-1}$, and $2.4 \mathrm{~nm}$, respectively. The employment of bentonite in the spent oil treatment led to blockage of open pores by the adsorption of heavy organic contaminants resulted in a material with low surface area with the limited number of mesopores.

The morphology of solid waste particles was examined by FESEM in Fig. 1e in which the micrograph reveals that the used starting material predominantly contains irregular shape of agglomerates with blockage texture. In fact the most of nanoparticles, $<10 \mathrm{~nm}$, were agglomerated, and formed the particles 
larger than $100 \mathrm{~nm}$. It seems that the nanoparticles were interconnected by organic compounds, leading to formation of semi-spherical large particles. The several semi-spherical nanoparticles stacked together in form of agglomerates, showing well-bonded structure rather than detached nanoparticles.

The X-ray pattern, and FTIR spectrum of boehmite, which used to compensate the lack of Al, are represented in Fig. $1 \mathrm{f}$. The XRD pattern could be indexed as JCPDS No. 01-083-2384. The well-defined abroad peaks corresponding to diffraction angles of $14.3,28.3,38.5,49.3$, and $55.5^{\circ}$ are related to (020), (120), (031), (200) and (002) planes, revealing the orthorhombic structure, and small crystallites. In fact, the used powder is classified as a pseudo-boehmite because the peaks are not intensely sharp. The Fourier transform infrared spectrum of boehmite reveals that the signal at wave number of $3662 \mathrm{~cm}^{-1}$ is related to the stretching vibration of $\mathrm{Al}-\mathrm{OH}$. The abroad absorption band observed at wave number of $3437 \mathrm{~cm}^{-1}$ is ascribed to hydroxyl stretching vibration while the band at $1640 \mathrm{~cm}^{-1}$ is due to $0-\mathrm{H}$ bending vibration. The signals at 1074 , and $484 \mathrm{~cm}^{-1}$ are believed to be due to $(\mathrm{OH})-\mathrm{Al}=0$ vibration corresponded to $\mathrm{AlO}_{4}$ groups, and the other bands observable in the wave number of 745 , and $619 \mathrm{~cm}^{-1}$ are assigned to (AlO)-O-H in $\mathrm{AlO}_{6}$ group. The signal in $1520 \mathrm{~cm}^{-1}$ is due to vibration in carbonate group.

\subsection{Determination of proper alkali and boehmite ratios}

In order to determine the proper alkali ratio for the deletion of opal CT, calcite, and feldspar from the solid waste, the mentioned factor was changed from 1.00 to 2.00, and the related XRD patterns are represented in Fig. 2a. The results indicate the predominance formation of amorphous phase with partially recrystallization of unknown aluminosilicates. The opal CT, calcite, and feldspar peaks were disappeared due to effective alkali fusion. Although the lower content of sodium hydroxide, AR: 1.00 , is sufficient to delete the non-clay impurities, the aluminum lack should be compensated from the other resources to convert the amorphous phase into zeolite $A$. Therefore, the investigation should be conducted to verify this methodology based on aluminum resource composition. According to the XRD patterns displayed in

Fig. 2b, boehmite with limited content, BR: 0.40, was used to convert the waste into zeolite structures. The identification of phases was carried out by Joint Committee on Powder Diffraction Standard (JCPDS). The use of boehmite powder in mix with solid waste led to recrystallization of zeolite A. Although the fusion performance was not noticeable when the alkali ratio was adjusted at the level of 1.00 , the synergy effect of boehmite in mixture with $\mathrm{NaOH}$, and solid waste occurred in higher $\mathrm{AR},>1.33$. The XRD results revealed that the higher content of $\mathrm{NaOH}$ led to formation of an impure zeolite A powder in which hydroxysodalite (HS) was partially recrystallized simultaneously.

The structural changes that occur in the solid waste after mixing with boehmite powder should be studied to determine the proper content of Al resource for the production of relatively pure zeolite A. To achieve this aim, the boehmite ratio was changed from 0.40 to 0.53 in which the alkali ratio was adjusted at two levels, 1.67, and 2.00. Figure 3 shows the XRD patterns of products produced with different boehmite ratios. The all patterns display well defined reflections related to LTA structure developed by the employment of boehmite. The peaks correspond to the reflections from (101), and (211) are typical characteristic of hydroxysodalite. The powders fabricated with the minimal content of boehmite were 
composed of zeolite A as a desired phase, and HS as an impurity. With increment in boehmite ratio, the peak intensity of HS disappeared, although a decline in LTA peak intensity was observable. Si, and Al dissolution in the melted phase is quite severe with strong alkalinity. This phenomenon is attributed to the structural disorder that occurs in the solid waste minerals, which affects the crystalline characteristic of final product by the development of amorphous phase. The peak intensity was increased, and narrowed by rise in the boehmite ratio up to 0.53 . However, the changes in the crystallinity not only is affected by boehmite ratio, but the alkalinity plays effective role in the recrystallization, and purity of powder. It should be emphasized that the crystallinity of powder produced with the maximal alkalinity, and boehmite ratio is clearly higher than those obtained in other conditions. The diffraction intensity of LTA phase tended to be relatively larger with adjusting the alkalinity at 2.00 , and boehmite ratio in 0.53 . According to the obtained results, it seems that LTA structure is formed easily by the fusion of solid waste in the presence of boehmite.

\subsection{Effect of fusion temperature on zeolite structure}

The XRD patterns of powders produced via the fusion at different temperatures, $600-800{ }^{\circ} \mathrm{C}$, are shown in Fig. 4 in which AR, and BR were fixed at the levels of 2.00, and 0.53 , respectively. LTA phase is the major crystalline structure, and the purity of powder is not significantly affected by the fusion temperature, Fig. 4a. The diffraction intensities of LTA phase reduced through the fusion at $700{ }^{\circ} \mathrm{C}$ while these peaks were intensive due to fusion at $800^{\circ} \mathrm{C}$. The dissolution of silicon, and aluminum in the amorphous phase into an alkaline solution, and interactions with particle surface led to deposition of aluminosilicate gel which could be converted to LTA structure under the hydrothermal condition. The results suggest that the silica, and alumina contents dissolved in water was insufficient for the recrystallization of zeolite $A$ when fusion was carried out at $700{ }^{\circ} \mathrm{C}$. The rate of dissolution with extension of amorphous phase caused the rapidly recrystallization of zeolite $A$. On the other hand, the heat treatment at higher temperature resulted in the amorphous particles with larger size which could be converted to a crystalline structure. Therefore, the crystallinity of zeolite A reached the maximal level with fusion at $800^{\circ} \mathrm{C}$, and influenced the opacity, and whiteness of final product. The remained organic ash in the powder produced by fusion at $600^{\circ} \mathrm{C}$ created a gray shade.

\subsection{Effect of aging time on zeolite structure}

Figure 5 displays the changes in the structure of zeolites produced via aging at different times. The composition prepared with $A R$, and $B R$ of 2.00 , and 0.53 was treated at $600^{\circ} \mathrm{C}$, and then aged within 3$24 \mathrm{~h}$. As previously explained, the thermally treated composite which was aged for $3 \mathrm{~h}$ could be converted to zeolite A, Fig. 5a. The aging at longer times, 12-24 h, led to acceleration of nucleation, and reduction of particle size due to limited crystallization time, $3 \mathrm{~h}$. Therefore, aging amorphous aluminosilicate favors for nucleation, and prevents the growth of particles in the hydrothermal stage. Also the hydroxysodalite content is negligible in the all produced powders. Indeed, the age of amorphous composite at ambient temperature could not affect the crystallite type. Consequently, a more stable nuclei was formed, and the significant difference was not observed after aging within 12-24 h. More detail can be acquired by 
calculation of relative crystallinity $(\mathrm{RC})$ by considering a commercial zeolite $\mathrm{A}$ as a reference through the following equation:

$\mathrm{RC}=\frac{\sum \mathrm{I}_{z}}{\sum \mathrm{I}_{\mathrm{r}}} \times 100$

where $I_{z}$ and $I_{r}$. are the intensities of produced, and reference material peaks respectively. Based on the XRD patterns represented in Fig. 5a, the relative crystallinity of fabricated powders is illustrated versus aging time as illustrated in Fig. $5 \mathrm{~b}$. The extension of aging time from 3 to $24 \mathrm{~h}$ led to a decline in relative crystallinity from 100 to $38 \%$. A sharp decrease in crystallinity occurred after $12 \mathrm{~h}$. By taking into account the error margin, the significant difference was not seen in crystallinity with rise in aging time after $12 \mathrm{~h}$. Silicon is more easily soluble into alkali solution compared to aluminum. The interconnection of silicon with $\mathrm{AlO}_{4}$ group could create more nuclei. As a result, a drop occurred in the relative crystallinity.

\subsection{Effect of sodium aluminate on zeolite structure}

As well-known, the content of $\mathrm{Si}$, and $\mathrm{Al}$ elements should be controlled to achieve zeolite A. Chemically, this type of zeolites is produced by Si/Al ratio in the range of 0.94-1.05. Consequently, the desirable structure can be theoretically created from different aluminum resources like boehmite, and sodium aluminate. To concern the sodium aluminate content to product structure, the SAR/AR was changed from zero to 1.01 in which the boehmite ratio was adjusted at the level of 0.53 . After the fusion of starting compositions at 600 , and $800{ }^{\circ} \mathrm{C}$, the given content of sodium aluminate was added before the aging step. Figure 6 shows the XRD patterns of zeolite powders produced with different SAR/AR ratios. Although, the negligible content of hydroxysodalite was formed within the studied range, LTA was found as dominant phase. The all patterns are characterized by well-defined reflections of zeolite A. As Al/ $\mathrm{Na}$ ratio increases in the solution, the diffraction peaks of LTA become weaker for the products fabricated in two fusion temperatures, suggesting the higher aluminum ratio is unfavorable to convert the amorphous phase into zeolite A. Obviously, the variation in SAR/AR ratio changes the zeolite A content which is probably due to the content of dissolved silicon, and aluminum elements in the hydrothermal system. Although silica in the amorphous phase could dissolve in hot alkali solution but, the dissolution retards with decline in $\mathrm{NaOH}$ content within the short reaction time, $3 \mathrm{~h}$. The soluble aluminosilicate phase can be produce by increase in content of sodium hydroxide in the fusion stage prior to submitting into the hydrothermal treatment. The silicon concentration is lower than the aluminum concentration, leading to reduction in zeolite $\mathrm{A}$ content. Though the fusion at $800^{\circ} \mathrm{C}$ could create higher content of amorphous phase, the transformation into the soluble phase is governed by alkalinity. Therefore, the recrystallization could not considerably be affected by fusion temperature within the short time.

It should be also verified the replacement of boehmite with sodium aluminate on crystalline structure of powders. Figure 7a depicts the XRD patterns of products fabricated with different SAR ratios in which AR was adjusted at level of 2.00. In contrast to replacement of $\mathrm{NaOH}$ with sodium aluminate, the substitution of $\mathrm{AlOOH}$ by $\mathrm{NaAlO}_{2}$ caused to continuous reduction in the intensity of LTA peaks. The modified composite, SAR: 0.40 , showed the structural change, leading to totally transformation of LTA phase into 
HS. The hydroxysodalite peaks progressively disappeared with further increment in SAR, 0.74. The amorphous phase become more reactive with decline in boehmite content in the starting composition, dissolving easily during aging, and the hydrothermal treatment. The reduction in LTA peak intensities was expected because of change in $\mathrm{Al} / \mathrm{Na}$ ratio due to employment of sodium aluminate. The fused material could alter the $\mathrm{Si}$, and $\mathrm{Al}$ concentrations in the alkali solution. The decrease in $\mathrm{Al} / \mathrm{Na}$ ratio in the solution favors for the recrystallization of HS.

The FTIR spectra of zeolite A, and hydroxysodalite fabricated by the employment of boehmite, and sodium aluminate are illustrated in Fig. $7 \mathrm{~b}$ in which the corresponding band assignments are highlighted. The powders have similar characteristic signals due similarity in structures. In the $\mathrm{OH}$ stretching region, the both composition show two prominent bands at 3410 , and $1640 \mathrm{~cm}^{-1}$, corresponding to hydrogen bond vibrations originated from adsorbed water. The weak bands observed at 1470 , and $1410 \mathrm{~cm}^{-1}$ are assigned to the carbonate groups existed in the solid waste. The IR peaks at 993 , and $555 \mathrm{~cm}^{-1}$ can be assigned to the internal asymmetric stretching vibration of Si-O or Al-O. The peak at $457 \mathrm{~cm}^{-1}$ is attributed to bending vibration of Si-O or Al-O vibrations. The band at $660 \mathrm{~cm}^{-1}$ is related to Si-O-Na vibration which is detected in zeolite $A$, and hydroxysodalite structure.

\subsection{Morphology of produced powders}

The FESEM image of zeolite powder produced with AR, and BR ratios of 1.67, and 0.40 is shown in Fig. 8 . As explained before, the powder is a mixture of zeolite $A$, and hydroxysodalite. The morphology of particles was identified as a mixture of regular, and irregular shapes which were distributed, randomly. In fact, the cubic LTA phase is more conducive to form in the hydrothermal stage due to application of boehmite. Commonly, the agglomerates of HS nanoparticles with irregular shape were formed extensively, proving the result obtained based on XRD analysis. There are some cabbage-like clusters which contain semi-spherical nanoparticles, $<200 \mathrm{~nm}$. The ball-like structure, which is well-known morphology for hydroxysodalite particles, was destroyed obviously. In addition, the HS nanoparticles were distributed onto the cubic LTA particles, $<500 \mathrm{~nm}$, making the morphology more irregular. The rough surface of hydrosodalite has irregular holes while the LTA crystallite displays a smooth surface with the curvature edges.

The SEM image of powder prepared with proper AR, 2.00, and BR, 0.53 , is represented in Fig. 9a in which the starting composite was treated at $600^{\circ} \mathrm{C}$. The image shows an individual cubic morphology, confirming the formation LTA structure as observed in XRD pattern. In order to achieve a reliable result about particle morphology, the microstructure was observed by higher magnification through FESEM image as represented in Fig. 9b. A crystalline phase was identified as regular cubic particles with the rounded edges which was covered by nanoparticles. The formation of hydroxysodalite nanoparticles, < $20 \mathrm{~nm}$, over the smooth surface of zeolite $\mathrm{A},<500 \mathrm{~nm}$, is evident. Also, the cubic particles seem to be mesoporous which is a clear evidence for the production of zeolite from the clay based materials. The main morphological feature observed for the zeolite produced by the treatment at $800{ }^{\circ} \mathrm{C}$ is typically cubic structure with the sharp edges, Fig. 9c, in which the LTA crystallites were covered with limited 
number of hydroxysodalite nanoparticles. The micrograph represents a dense cubic structure due to fusion at higher temperature, leading to elimination of micropores.

The ball-like agglomerates containing mainly round nano-plates with irregular shape can be observed in the microstructure of hydroxysodalite as represented in Fig. $9 \mathrm{~d}$. The many large clusters with irregular morphology were created with limited boehmite content, BR: 0.13 , in the presence of sodium aluminate with SAR of 0.40 . The mean diameter of ball-like agglomerates is estimated to be $0.5-1.0 \mu \mathrm{m}$. The presence of mesopores with a diameter smaller than $10 \mathrm{~nm}$ onto the nano-plates caused the formation of rough structure which is favorable for the extension of surface area.

\subsection{Textural characteristics of zeolite powders}

The nitrogen adsorption-desorption isotherms of zeolite $A$, and hydroxysodalite produced by combination of waste, boehmite, and sodium aluminate are plotted in Fig. 10a. Regardless the content of $\mathrm{N}_{2}$ adsorbed by obtained zeolites, the plots are convex respect to the relative pressure which is the wellknown as type III isotherm. The weak adsorbate-adsorbent interactions are observed for zeolite $A$ fabricated via fusion at 600 , and $800{ }^{\circ} \mathrm{C}$ which are mostly contain mesopores. The adsorption isotherm of HS also shows type III curve with H3 hysteresis loop, formed at the relative pressure of $0.45-0.99$. However, when the relative pressure, $P / P_{0}$, is close to 0.75 , the isotherm slope changes sharply in which not only the adsorption is completed onto the outer particle surfaces, but also occurs within the meso, and macropores. The slit-like mesopores were created within the plate-like nanoparticles of hydroxysodalite. Furthermore, the pores are frequently distributed in the meso range, 2-50 nm, according to the cumulative pore volume plot as shown in Fig. 10b. The basic textural parameters, including specific surface area, pore volume, average pore diameter of zeolite products are reported in Table 2, displayed lower specific surface area for obtained zeolite $A, 12-13 \mathrm{~m}^{2} \mathrm{~g}^{-1}$, and pore volume in contrast with those obtained for hydroxysodalite. Although the differences between the textural properties of zeolite $A$ powders seem to be negligible, the surface area of $\mathrm{HS}, 77 \mathrm{~m}^{2} \mathrm{~g}^{-1}$, is 6 times higher than those obtained for zeolite A powders. A larger surface area, and pore volume can be accommodated to the extended number of mesopores.

Table 2

Textural properties of produced zeolite A, and hydroxysodalite powders.

\begin{tabular}{|llllll|}
\hline BR & SAR & $\begin{array}{l}\text { Fusion } \\
\text { temperature }\left({ }^{\circ} \mathbf{C}\right)\end{array}$ & $\begin{array}{l}\text { Specific surface area } \\
\left(\mathbf{m}^{2} \cdot \mathbf{g}^{-1}\right)\end{array}$ & $\begin{array}{l}\text { Pore volume } \\
\left(\mathbf{c m}^{3} \cdot \mathbf{g}^{-1}\right)\end{array}$ & $\begin{array}{l}\text { Average pore } \\
\text { size }(\mathrm{nm})\end{array}$ \\
\hline 0.53 & 600 & 13.2 & 0.0601 & 3.7 \\
\hline 0.53 & 800 & 12.1 & 0.0493 & 3.7 \\
\hline 0.13 & 0.40 & 600 & 77.3 & 0.3793 & 4.8 \\
\hline
\end{tabular}

\subsection{Cation exchange capacity of produced zeolites}


In order to evaluate the cation exchange capacity of produced zeolite A, hydroxysodalite, and or a mixture of mentioned phases, hard water containing calcium chloride was treated with above composites, and the CEC values were compared as reported in Table 3. The minimal cation exchange capacity is related to powder fabricated in the presence of sodium aluminate, SAR: 0.40 , in which HS was recrystallized perfectly. Hydroxysodalite structure is denser and has a small pore size which is responsible for lower CEC. The zeolite A produced via the application of boehmite, AR: 2.00 , and BR: 0.53 , showed the maximal CEC even with fusion at $800{ }^{\circ} \mathrm{C}$ which was due to well recrystallization of LTA structure, including larger pore size in comparison to that for sodalite. This phenomenon was verified by additional tests on compounds, containing both of zeolite A, and hydroxysodalite. Notably, a drop in CEC occurred in the powders produced with lower alkalinity or boehmite ratio because of reduction in relative crystallinity, and formation of HS, thus indicating insufficient capability for cation exchange. Instead, the CEC of powder prepared in longer time, $12 \mathrm{~h}$, displayed a significant value ascribable to recrystallization of smaller crystallites, and absence of HS. Therefore, the purity, and relative crystallinity of zeolite A are of great importance in the water softening process.

Table 3

Cation exchange capacity of zeolite compounds produced from solid waste at different conditions.

\begin{tabular}{|lllllll|}
\hline AR & BR & SAR & $\begin{array}{l}\text { Fusion temperature } \\
\left({ }^{\circ} \mathrm{C}\right)\end{array}$ & $\begin{array}{l}\text { Aging time } \\
(\mathrm{h})\end{array}$ & $\begin{array}{l}\text { CEC } \\
(\mathrm{mg} \mathrm{CaCO}\end{array}$ & $\begin{array}{l}\text { LTA } / \mathrm{g}) \\
(\%)\end{array}$ \\
\hline 1.67 & 0.40 & 600 & 3 & 131.4 & 98.1 \\
\hline 1.67 & 0.53 & 600 & 3 & 178.2 & 84.2 \\
\hline 2.00 & 0.53 & 600 & 3 & 182.7 & 100 \\
\hline 2.00 & 0.53 & 800 & 3 & 190.2 & 100 \\
\hline 2.00 & 0.53 & & 600 & 12 & 154.8 & 41.1 \\
\hline 2.00 & 0.13 & 0.40 & 600 & 3 & 73.7 & 0.0 \\
\hline
\end{tabular}

\section{Conclusions}

The current investigation was studied the conversion of solid waste deposited in the landfill of used motor oil recovery industries into the zeolite structure via the alkali fusion to manage the toxicity. The structure of products is considerably affected by alkalinity, boehmite content, sodium aluminate dose, fusion temperature, and aging time. According to the obtained results, the crystallinity, purity, and cation exchange capacity of produced zeolite $A$ are attributed to the change in alkalinity, and boehmite ratio which should be fixed at the level of 2.00 , and 0.53 , respectively to achieve maximal values. The composite treated at $800^{\circ} \mathrm{C}$ exhibited a higher CEC, $190 \mathrm{mg} \mathrm{g}^{-1}$, due to better recrystallization, and defect deletion although the slight decline was observed in the surface area, and pore volume with fusion at higher temperature. The crystallinity was found to inversely proportional to aging time, providing a 
condition to accelerate the production rate, reaching the proper compound within $6 \mathrm{~h}$. Briefly, the presence of sodium aluminate is only appropriate to achieve hydroxysodalite with larger specific surface area, 77 $\mathrm{m}^{2} \mathrm{~g}^{-1}$, preventing the formation of LTA structure. The represented pathway has a great potential as a facile, and novel platform due to discrimination for the management of hazardous solid waste because of eco-friendly nature, stability, and applicability in the water softening process.

\section{Declarations}

Ethics approval and consent to participate: Not applicable

Consent for publication: Not applicable

Availability of data and materials: The datasets used and/or analyzed during the current study are available from the corresponding author on reasonable request.

Competing interests: The authors declare that they have no competing interests.

Funding: No funding was received.

Authors' contributions: Fatemeh Amir Aslanzadeh Mamaghani: Experimentation, and Characterizations, Amin Salem: Supervision, Conceptualization, and Methodology, Shiva Salem: Consultation, Characterizations, Writing- Reviewing, and Editing.

\section{References}

1. Abdullahi T, Harun Z, Othman MHD (2017) A review on sustainable synthesis of zeolite from kaolinite resources via hydrothermal process. Adv Powder Technol 28(8):1827-1840. https://doi.org/10.1016/j.apt.2017.04.028

2. Anuwattana R, Khummongkol P (2009) Conventional hydrothermal synthesis of Na-A zeolite from cupola slag and aluminum sludge. J Hazard Mater 166:227-232. https://doi.org/10.1016/j.jhazmat.2008.11.020

3. Ayele L, Pérez-Pariente J, Chebude Y, Díaz I (2016) Conventional versus alkali fusion synthesis of zeolite A from low grade kaolin. Appl Clay Sci 132-133:485-490. https://doi.org/10.1016/j.clay.2016.07.019

4. Belviso C, Cannas C, Pinna N, Cavalcante F, Lettino A, Lotti P, Gatta GD (2020) Effect of red mud added to zeolite LTA synthesis: Where is Fe in the newly-formed material? Microporous Mesoporous Mater 298:110058. https://doi.org/10.1016/j.micromeso.2020.110058

5. Collins F, Rozhkovskaya A, Outram JG, Millar GJ (2020) A critical review of waste resources, synthesis, and applications for zeolite LTA. Microporous Mesoporous Mater 291:109667. https://doi.org/10.1016/j.micromeso.2019.109667 
6. Dusselier M, Davis ME (2018) Small-pore zeolites: Synthesis and catalysis. Chem Rev 118(11):5265-5329. https://doi.org/10.1021/acs.chemrev.7b00738

7. Foroughi M, Salem A, Salem Sh (2021) Characterization of phase transformation from low grade kaolin to zeolite LTA in fusion technique: Focus on quartz melting and crystallization in presence of $\mathrm{NaAlO}_{2}$. Mater Chem Phys 258:123892. https://doi.org/10.1016/j.matchemphys.2020.123892

8. García-Villén F, Flores-Ruíz E, Verdugo-Escamilla C, Huertas FJ (2018) Hydrothermal synthesis of zeolites using sanitary ware waste as a raw material. Appl Clay Sci 160:238-248.

https://doi.org/10.1016/j.clay.2018.02.004

9. Guerin TF (2008) Environmental liability and life-cycle management of used lubricating oils. Hazard Mater 160:256-264. https://doi.org/10.1016/j.jhazmat.2008.03.029

10. Jafari AJ, Hassanpour M (2015) Review analysis and comparison of used lubricants, regenerative technologies in the world. Resour Conserv Recycl 103:179-191.

https://doi.org/10.1016/j.resconrec.2015.07.026

11. Jin Y, Li L, Liu Z, Zhu S, Wang D (2021) Synthesis and characterization of low-cost zeolite NaA from coal gangue by hydrothermal method. Adv Powder Technol 32(3):791-801. https://doi.org/10.1016/j.apt.2021.01.024

12. Johnson EBG, Arshad SE (2014) Hydrothermally synthesized zeolites based on kaolinite: A review. Appl Clay Sci 97-98:215-221. https://doi.org/10.1016/j.clay.2014.06.005

13. Kuroki S, Hashishin T, Morikawa T, Yamashita K, Matsuda M (2019) Selective synthesis of zeolites A and $X$ from two industrial wastes: Crushed stone powder and aluminum ash. J Environ Manage 231:749-756. https://doi.org/10.1016/j.jenvman.2018.10.082

14. Ma H, Yao Q, Fu Y, Ma C, Dong X (2010) Synthesis of zeolite of type A from bentonite by alkali fusion activation using Na2CO3. Ind Eng Chem Res 49(2):454-458. https://doi.org/10.1021/ie901205y

15. Muriithi GN, Petrik LF, Doucet FJ (2020) Synthesis, characterisation and $\mathrm{CO}_{2}$ adsorption potential of $\mathrm{NaA}$ and $\mathrm{NaX}$ zeolites and hydrotalcite obtained from the same coal fly ash. $\mathrm{J} \mathrm{\textrm {CO } _ { 2 }}$ Util 36:220-230. https://doi.org/10.1016/j.jcou.2019.11.016

16. Salem A, Saghapour M (2015) Relationship between acidification factors and methylene blue uptake by Ca-bentonite: Optimisation and kinetic study. Chem Papers 70(2):153-163. https://doi.org/10.1515/chempap-2015-0195

17. Rozhkovskaya A, Rajapakse J, Millar GJ (2021a) Optimisation of zeolite LTA synthesis from alum sludge and the influence of the sludge source. J Environ Sci 99:130-142. https://doi.org/10.1016/j.jes.2020.06.019

18. Rozhkovskaya A, Rajapakse J, Millar GJ (2021b) Synthesis of high-quality zeolite LTA from alum sludge generated in drinking water treatment plants. J Environ Chem Eng 9(2):104751. https://doi.org/10.1016/j.jece.2020.104751

19. Savic I, Stojiljkovic S, Savic I, Gajic D (2014) Industrial application of clays and clay minerals. In: Wesley LR (ed) Clays and Clay Minerals Geological Origin, Mechanical Properties and Industrial 
Applications. Nova Science Publishers, Inc., New York, pp 379-402

20. Shabanzade H, Salem A, Salem Sh (2018) Management of adsorbent content in waste motor oil regeneration by spectrophotometrical study and effective acidification in production of nano-porous clay. Spectrochim Acta A Mol Biomol Spectrosc 202:214-221. https://doi.org/10.1016/j.saa.2018.05.056

21. Shabanzade H, Salem A, Salem Sh (2019) Efficient removal of contaminants from waste lubricant oil by nano-porous bentonite produced via microwave-assisted rapid activation: process identifications and optimization. Environ Sci Pollut Res 26:23257-23267. https://doi.org/10.1007/s11356-01905625-w

22. Shattar SFA, Zakaria NA, Foo KY (2020) One step acid activation of bentonite derived adsorbent for the effective remediation of the new generation of industrial pesticides. Sci Rep 20151:1-13. https://doi.org/10.1038/s41598-020-76723-w

23. Weitkamp J (2000) Zeolites and catalysis. Solid State lon 131:175-188. https://doi.org/10.1016/S0167-2738(00)00632-9

24. Yang L, Qian X, Yuan P, Bai H, Miki T, Men F, Li H, Nagasaka T (2019) Green synthesis of zeolite 4A using fly ash fused with synergism of $\mathrm{NaOH}$ and $\mathrm{Na}_{2} \mathrm{CO}_{3}$. J Clean Prod 212:250-260. https://doi.org/10.1016/j.jclepro.2018.11.259

25. Yoldi M, Fuentes-Ordoñez EG, Korili SA, Gil A (2019) Zeolite synthesis from industrial wastes. Microporous Mesoporous Mater 287:183-191. https://doi.org/10.1016/j.micromeso.2019.06.009

26. Zivica V, Palou MT (2015) Physico-chemical characterization of thermally treated bentonite. Compos Part B Eng 68:436-445. https://doi.org/10.1016/j.compositesb.2014.07.019

\section{Figures}



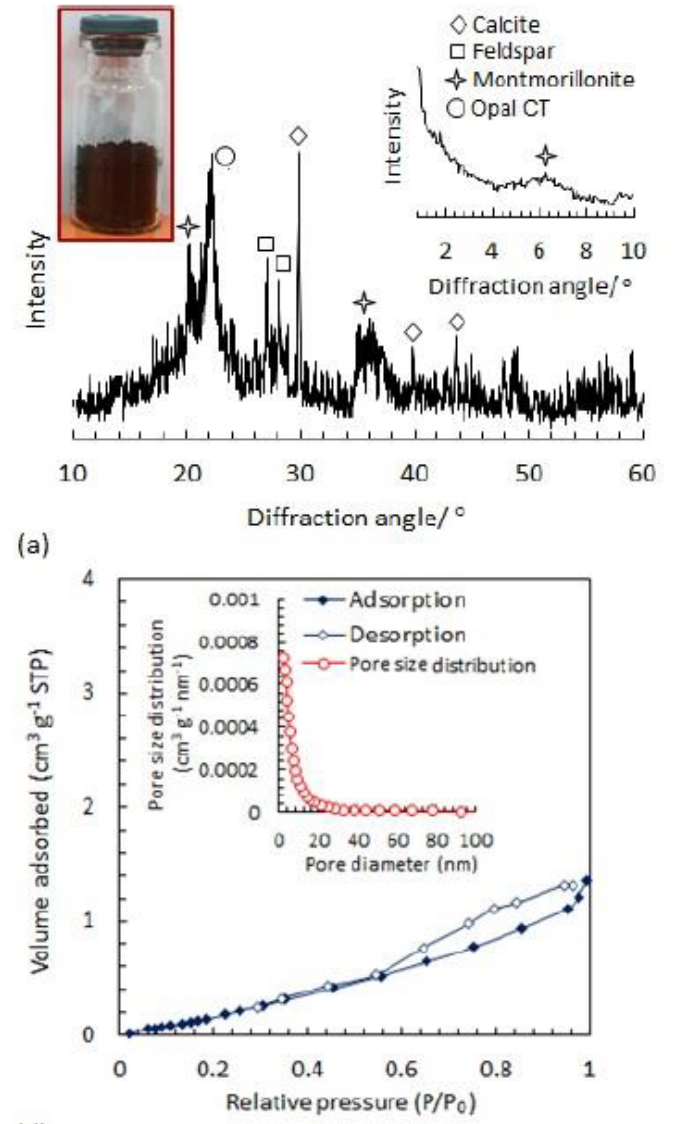

(d)

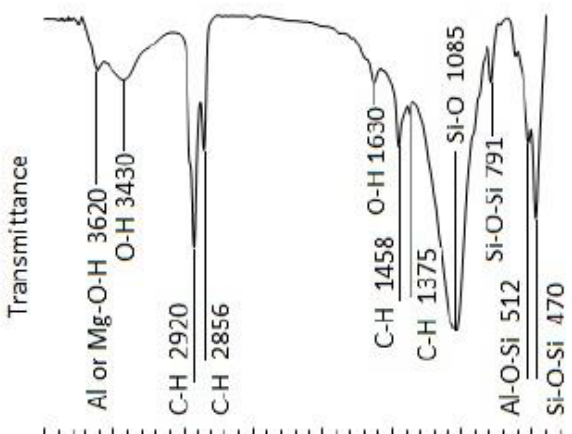

4000350030002500200015001000500

Wave number $\left(\mathrm{cm}^{-1}\right)$

(b)

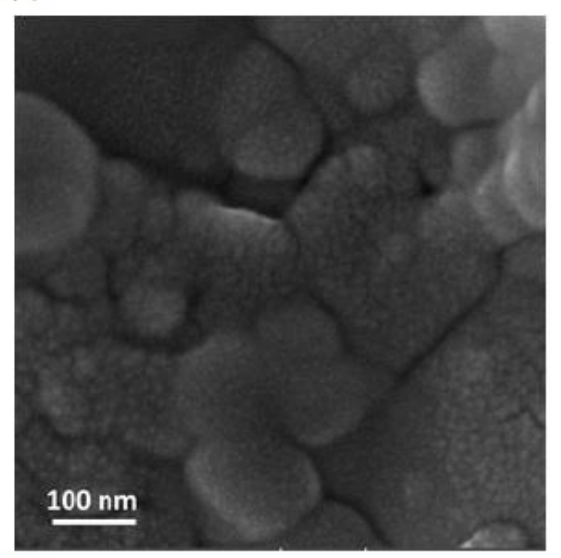

(e)

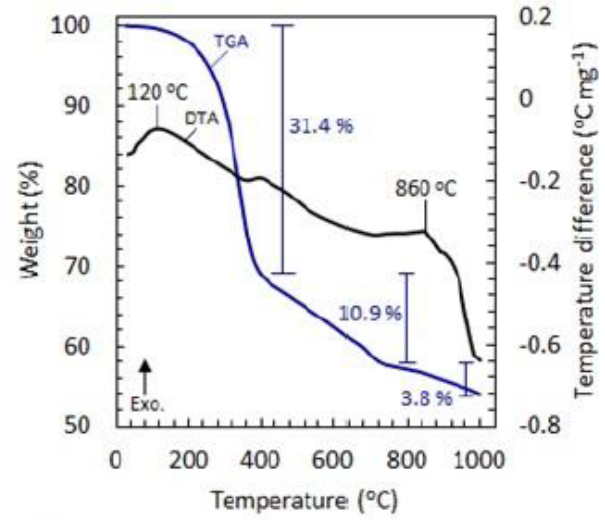

(c)
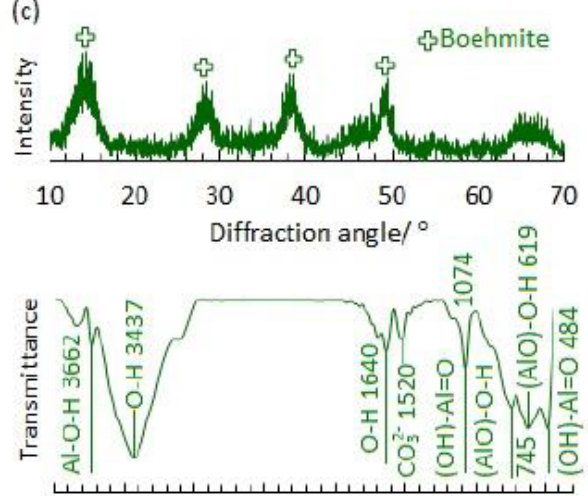

4000350030002500200015001000500 Wave number $\left(\mathrm{cm}^{-1}\right)$

(f)

\section{Figure 1}

Physico-chemical characteristics of used solid waste, and boehmite.

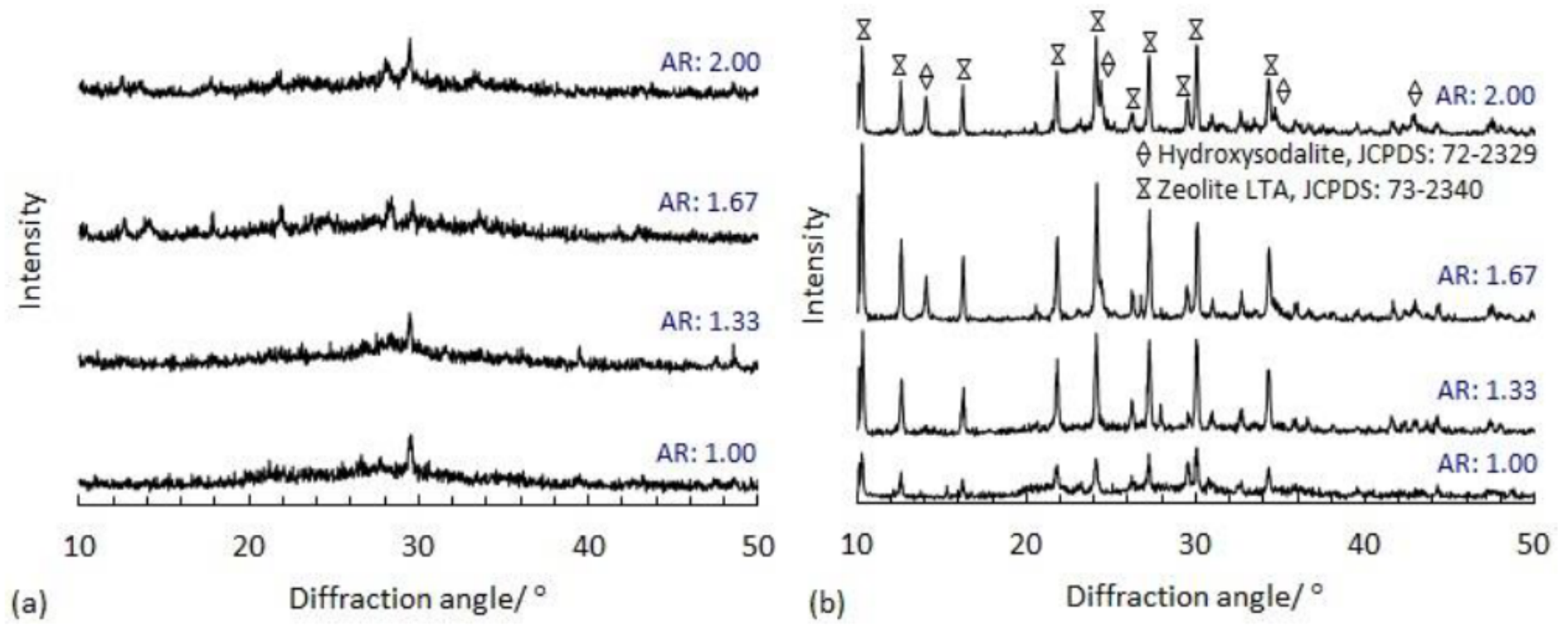

Figure 2

XRD patterns of composites prepared with different alkali ratios, treated at $600{ }^{\circ} \mathrm{C}$, (a) BR: zero, and (b) BR: 0.40 . 

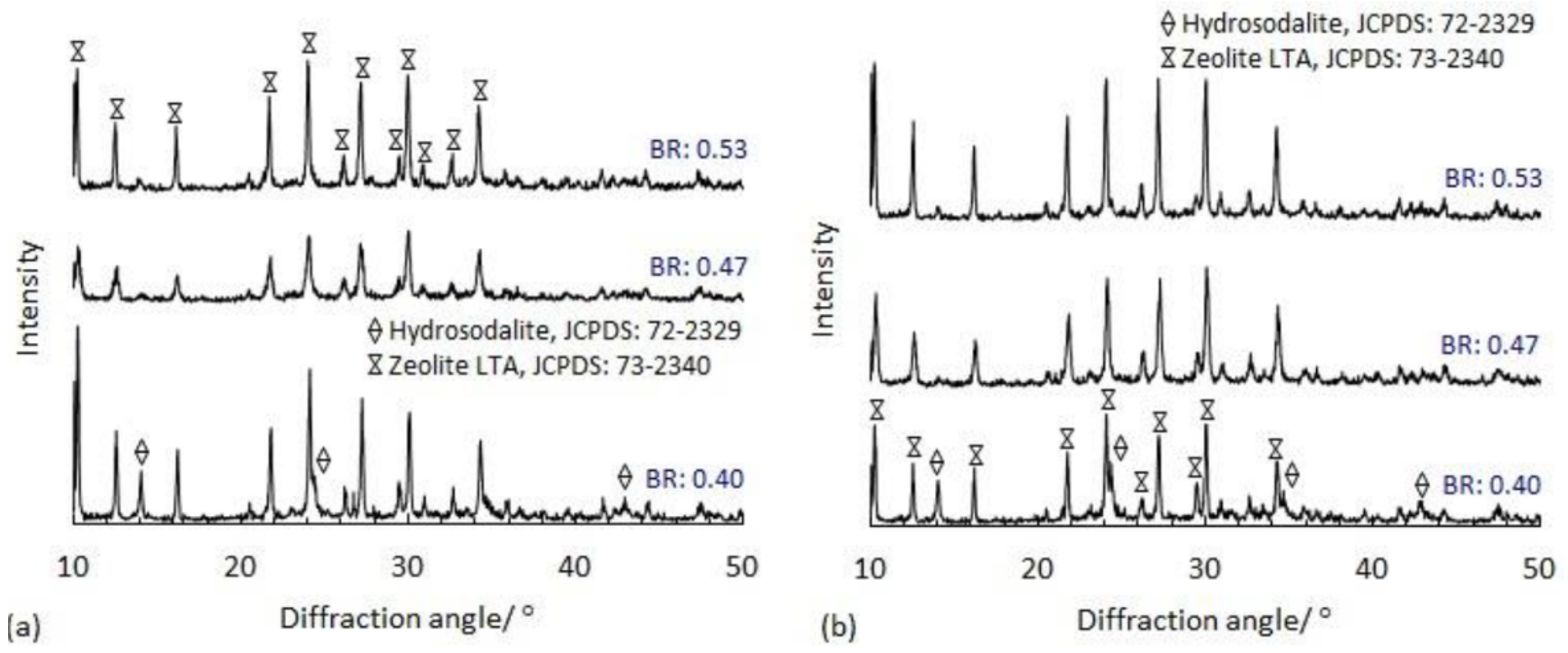

\section{Figure 3}

XRD patterns of composites prepared with different boehmite ratios, treated at $600{ }^{\circ} \mathrm{C}$, (a) AR: 1.67 , and (b) AR: 2.00 .
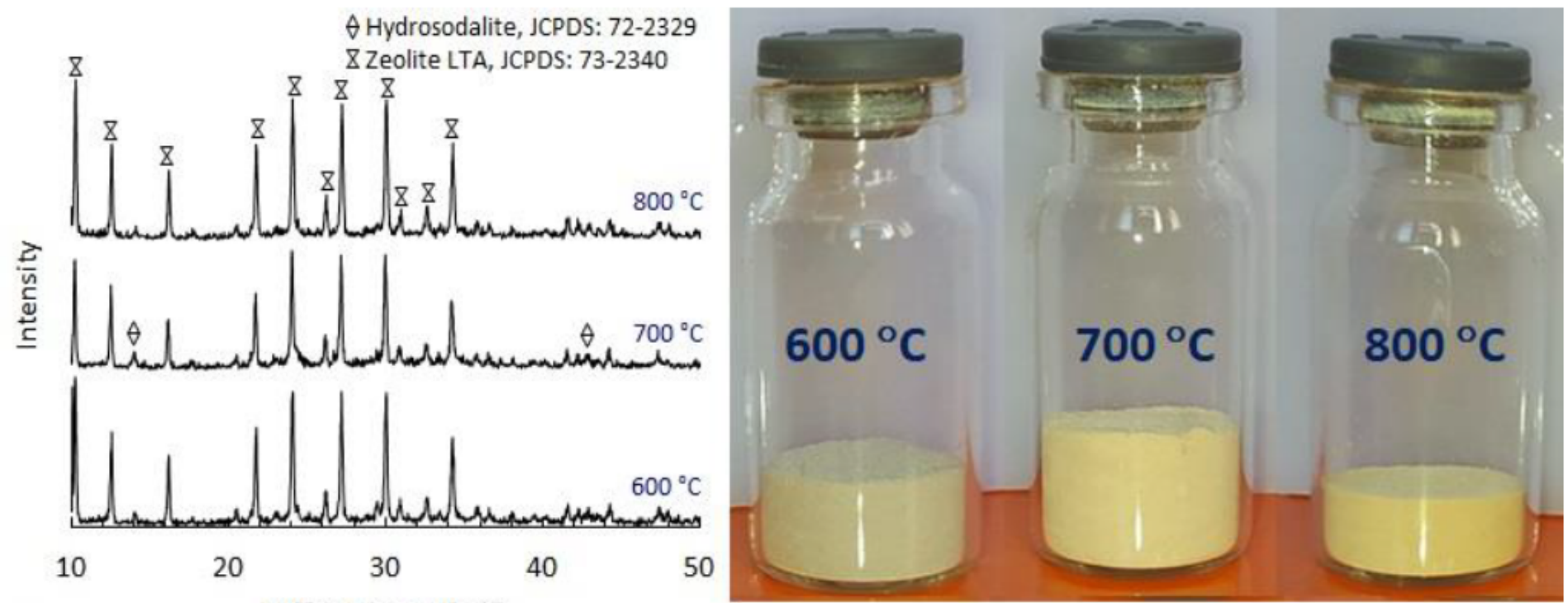

(a)

Diffraction angle/ ${ }^{\circ}$

(b)

Figure 4

Zeolites prepared by fusion at different temperatures, AR: 2.00, and BR: 0.53, (a) XRD patterns, and (b) obtained powder images. 
$\forall$ Hydrosodalite, JCPDS: $72-2329$

\& Zeolite LTA, JCPDS: 73-2340

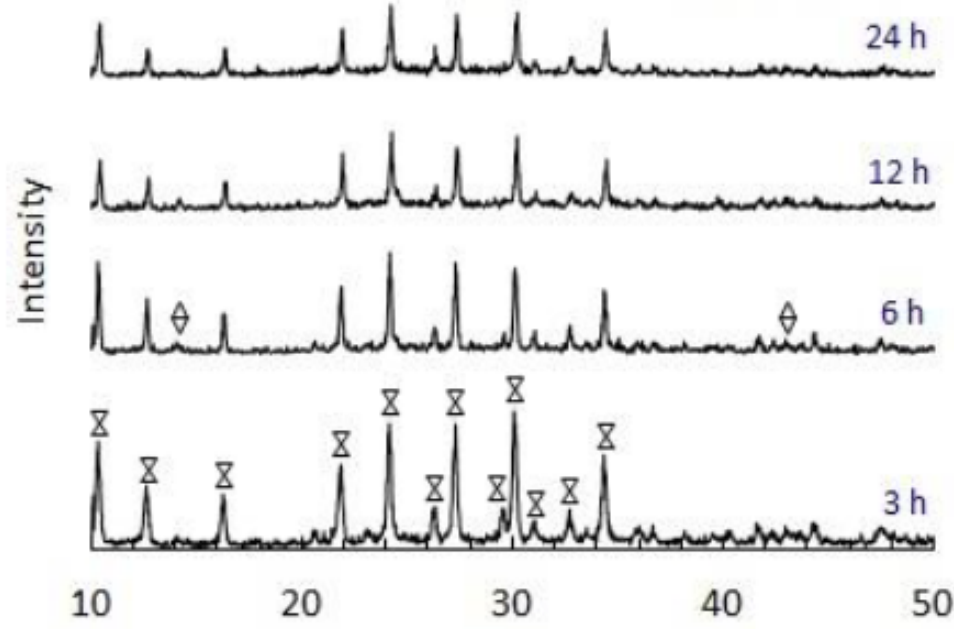

(a)

Diffraction angle/ ${ }^{\circ}$

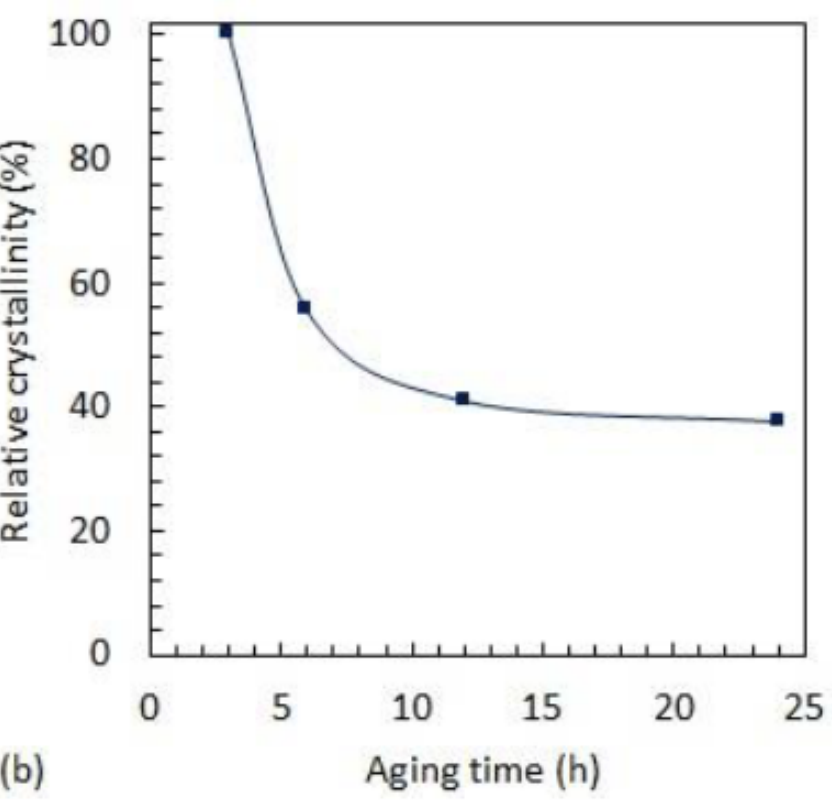

(b)

Figure 5

Zeolites prepared by aging at different times, treated at $600^{\circ} \mathrm{C}$, (a) XRD patterns, and (b) relative crystallinity.

A Hydroxysodalite, JCPDS: 72-2329

\& Zeolite LTA, JCPDS: $73-2340$

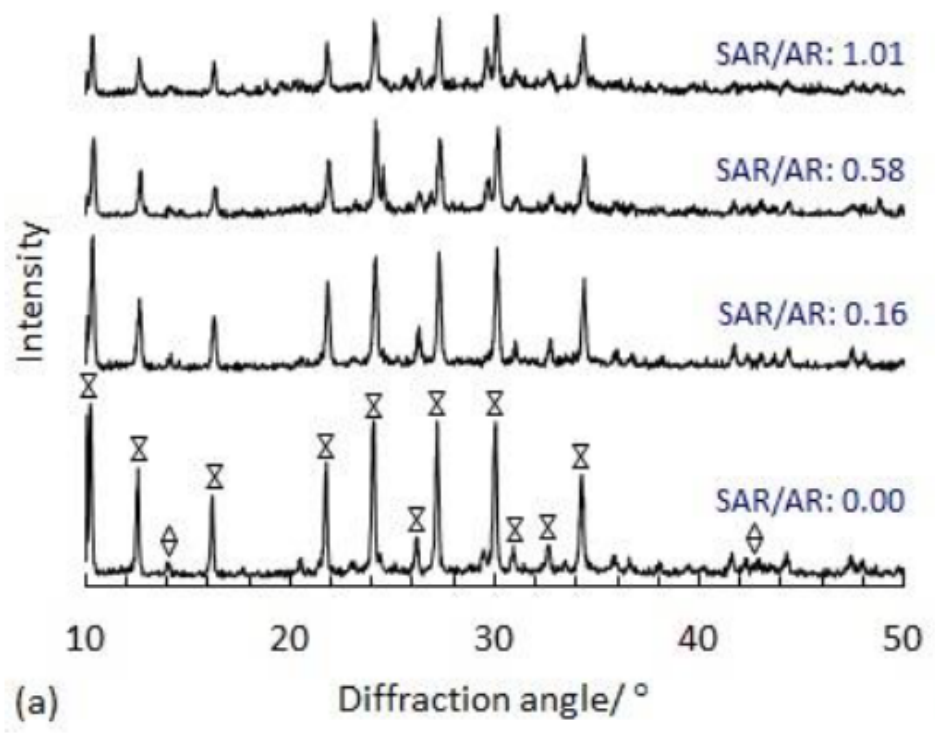

$\forall$ Hydroxysodalite, JCPDS: $72-2329$

\& Zeolite LTA, JCPDS: 73-2340

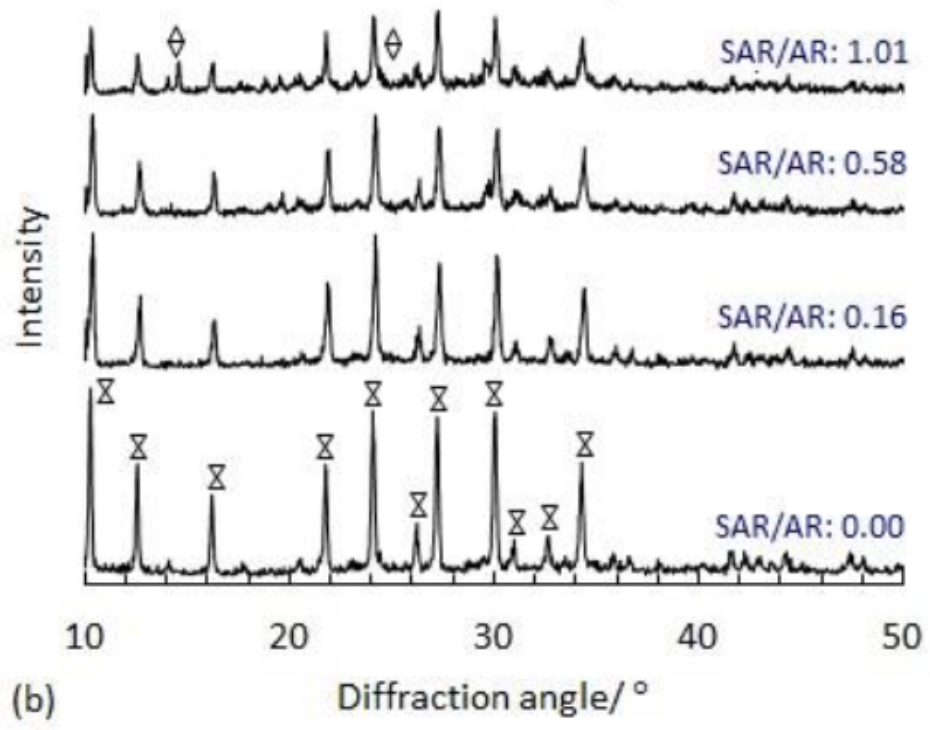

Figure 6

XRD patterns of composites prepared with different SAR/AR ratios, treated at (a) 600 , and (b) $800{ }^{\circ} \mathrm{C}$. 
SAR: 0.74

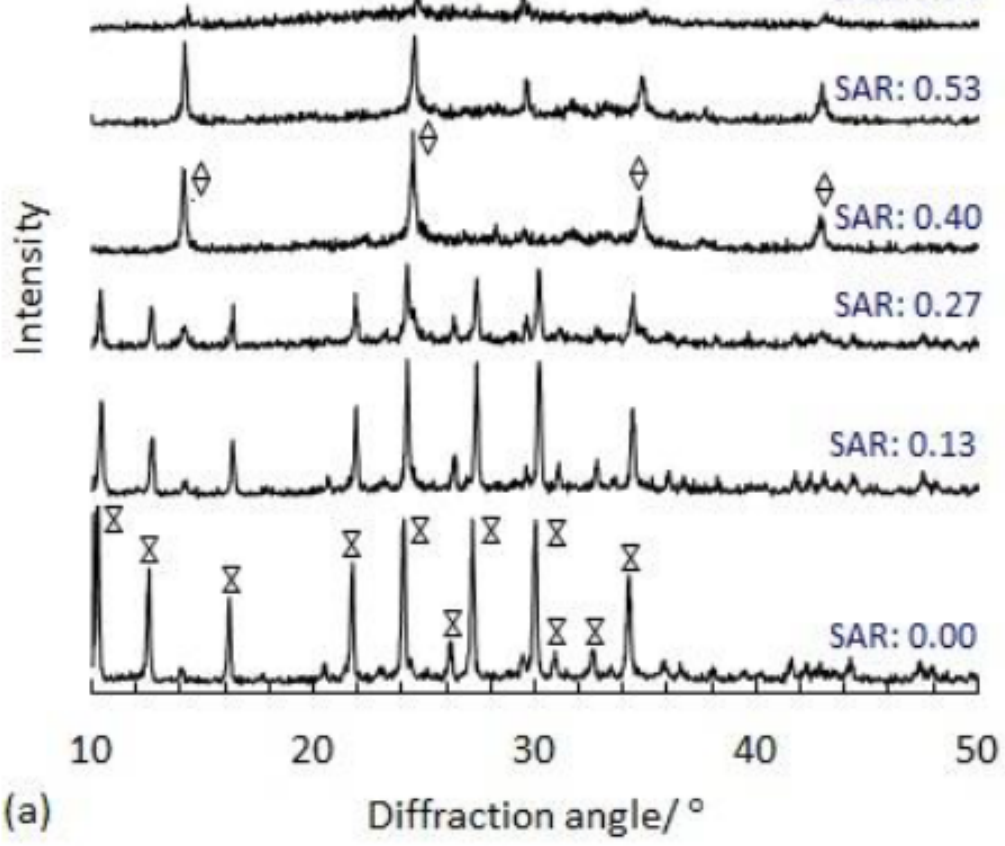

AR: 2.00 , BR: 0.13 , SAR: 0.40

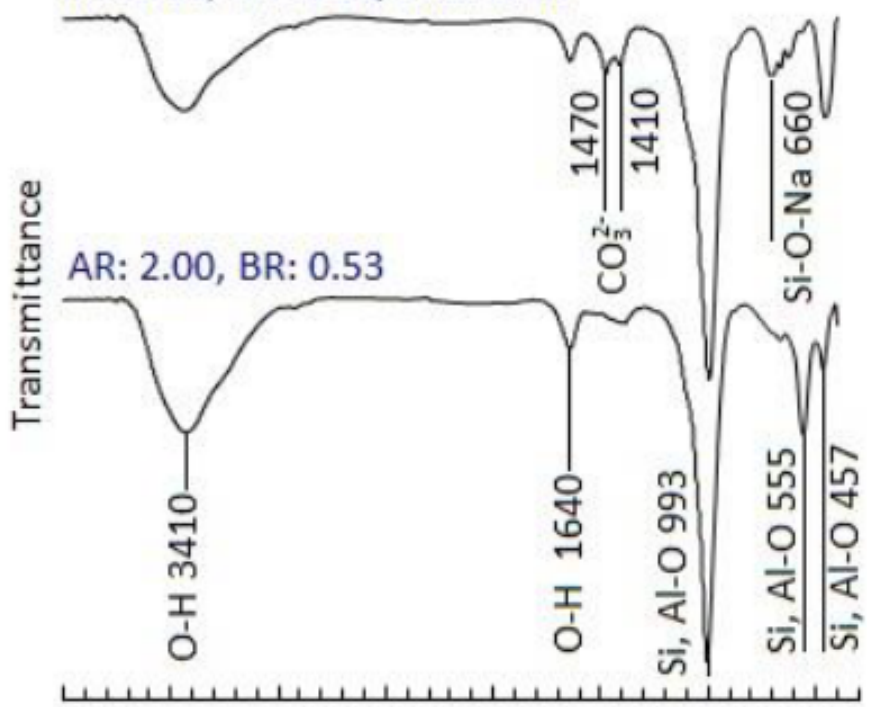

4000350030002500200015001000500 (b)

Wave number $\left(\mathrm{cm}^{-1}\right)$

Figure 7

Zeolites prepared with different sodium aluminate ratio, treated at $600{ }^{\circ} \mathrm{C},(\mathrm{a}) \mathrm{XRD}$ patterns, and (b) FTIR spectra.

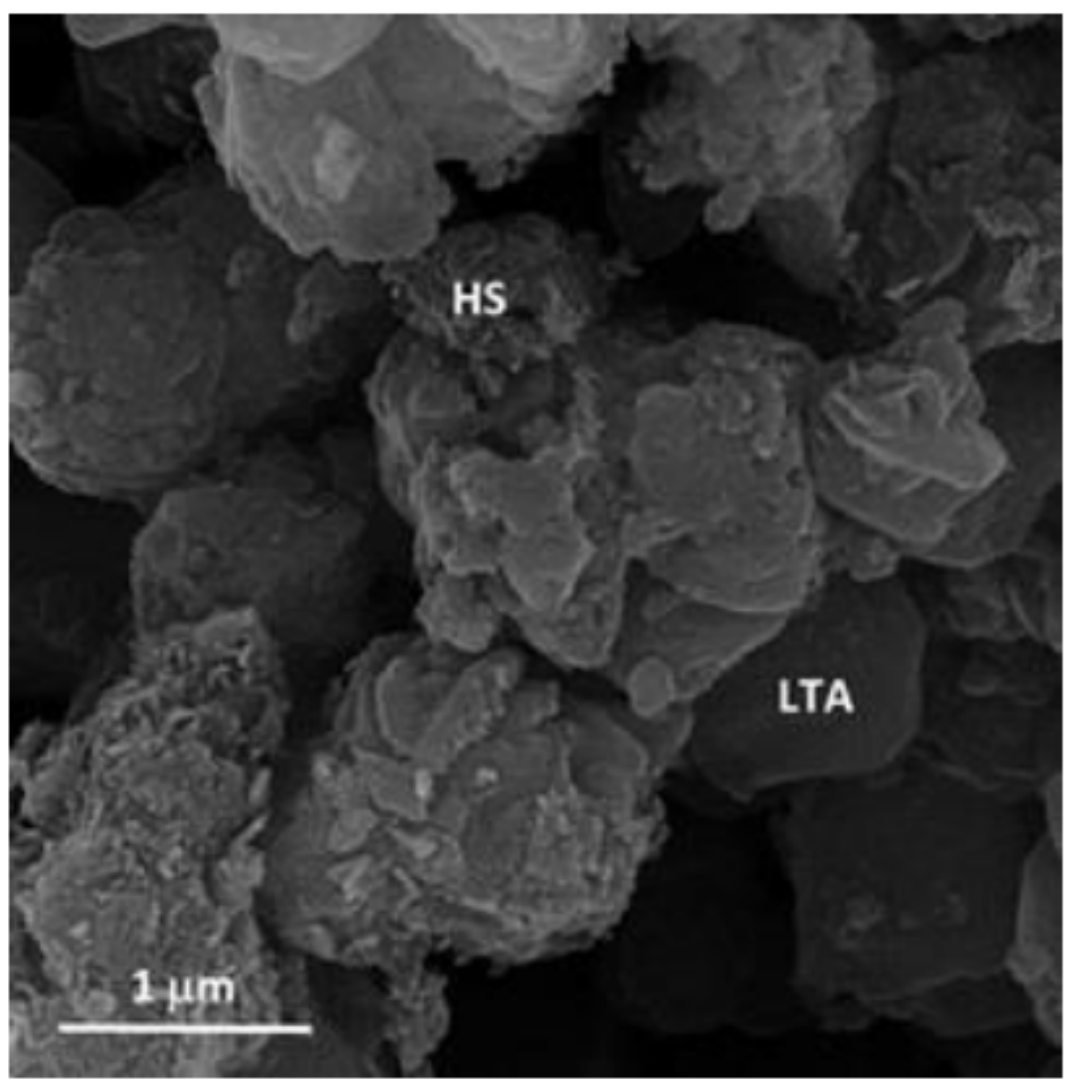

Figure 8 
FESEM image of powder produced with AR, and BR ratios of 1.67 , and 0.40 , treated at $600^{\circ} \mathrm{C}$.
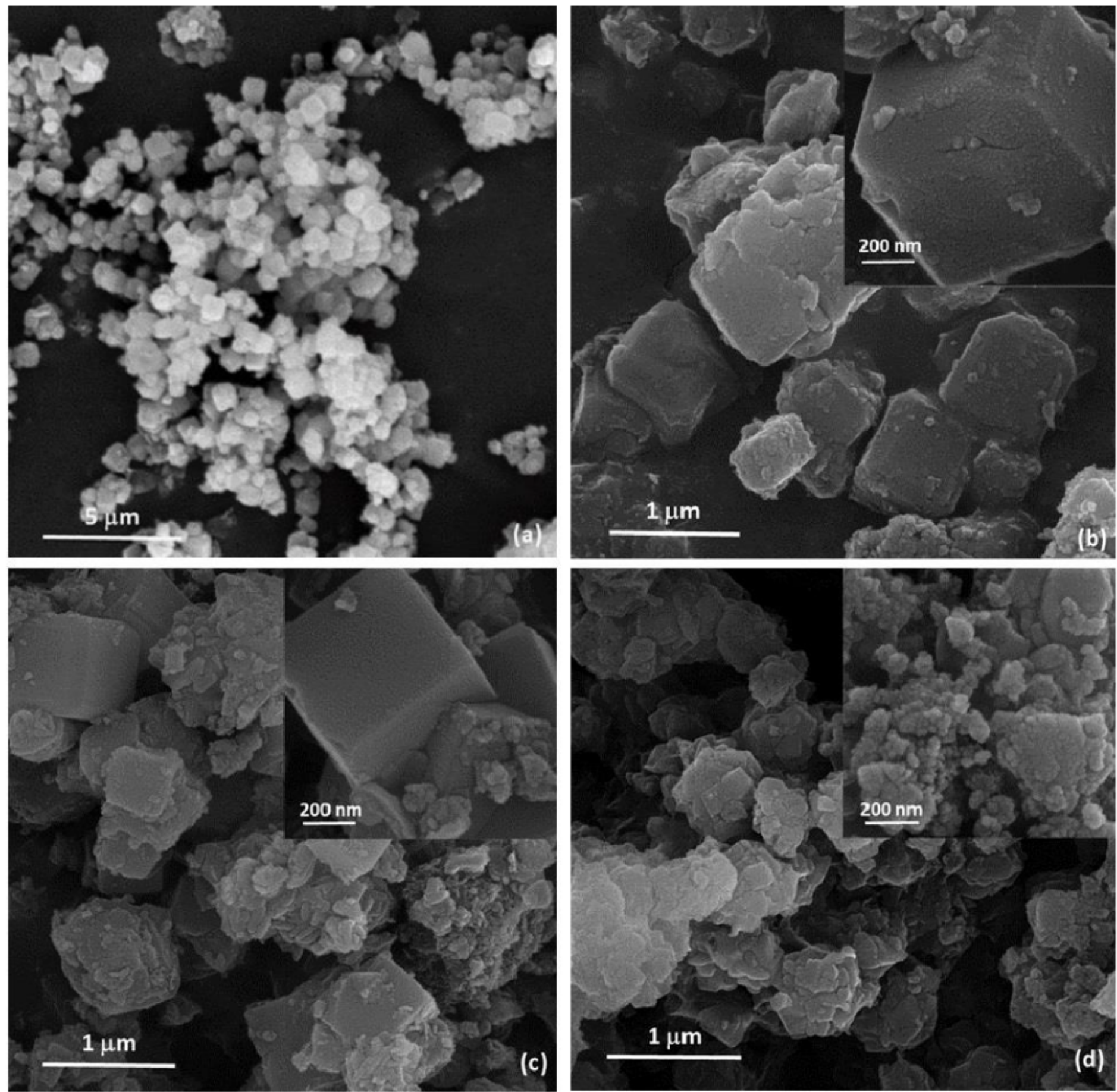

\section{Figure 9}

Microstructure of zeolite powders produced at different conditions, (a) SEM image, AR: 2.00, BR: 0.53, treated at $600^{\circ} \mathrm{C}$, (b) FESEM image, AR: 2.00, BR: 0.53, treated at $600^{\circ} \mathrm{C}$, (c) FESEM image, AR: $2.00, B R$ : 0.53 , treated at $800{ }^{\circ} \mathrm{C}$, and (d) FESEM image, AR: 2.00, BR: 0.13 , SAR: 0.40 , treated at $600^{\circ} \mathrm{C}$. 

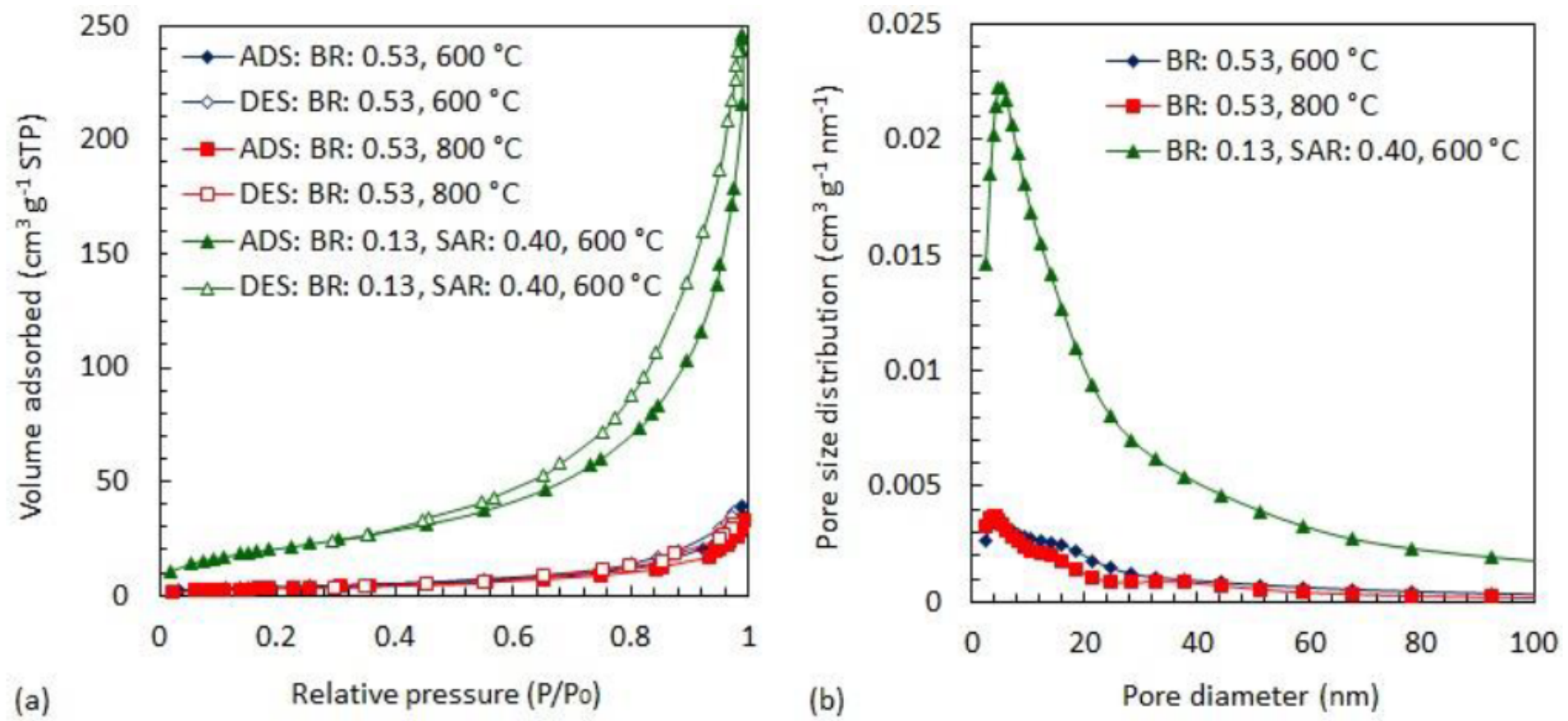

Figure 10

Textural properties of produced zeolites, (a) N2 adsorption-desorption isotherms, and (b) pore size distribution. 